\title{
VIGOR, DEDICAÇÃO, ABSORÇÃO: UMA ANÁLISE DA PERCEPÇÃO DE PROFISSIONAIS PÓS-GRẢDUANDOS SOBRE ENGAJAMENTO NO TRABALHO
}

\author{
Luciana Raquel Nunes Irineu Moura* \\ Lucas Charão-Brito** \\ Luis Felipe Dias Lopes***
}

RESUMO: O presente trabalho procurou investigar e analisar a percepção deprofissionais pós-graduandos sobre engajamento no trabalho (vigor, dedicação e absorção). Para tanto, esta pesquisa está pautada em um estudo descritivo e quantitativo a partir da utilização do instrumento de coleta de dados Utrecht Work Engagement Scale (UWES) de Schaufeli e Bakker (2003), aplicada em uma amostra de 147 profissionais pós-graduandos de uma instituição de ensino superior privada. Os resultados evidenciaram que a maioria dos profissionais pesquisados identificam-se com seu trabalho, uma vez que as atividades que desempenham possuem significado e propósito. Porém, estes profissionais também apresentaram-se com pouca dificuldade em desligar-se do trabalho, características presentes na geração Y.

PALAVRAS-CHAVE: Profissionais; Pós-graduação; Engajamento.

\section{VITALIT Y, DEDICATION, ABSORPTION: ANALYSIS OF POST- GRADUATE PROFESSIONALS' PERCEPTION ON COMMITMENT TO WORK}

ABSTRACT: The perception of post-graduate professionals on commitment to work (vitality, dedication and absorption) is investigated. Descriptive and quantitative research is based on the data collection tool called Utrecht Work Engagement Scale (UWES) by Schaufeli and Bakker (2003), applied to a sample of 147 post-graduate professionals of a private higher education institution. Results show that most professionals identify themselves with their work since their activities have meaning and target. However, they have scanty difficulty in quitting their job, typical of the $Y$ generation.

KEY WORDS: Professionals; Post-graduation; Commitment.

Mestranda em Administração pelo Programa de Pós-Graduação em Administração da Universidade Federal de Santa Maria (UFSM), Brasil.

** Doutorando em Administração pelo Programa de Pós-Graduação em Administração Universidade Federal de Santa Maria (UFSM), Brasil. E-mail: adm.lucascharao@hotmail.com

**** Docente titular de Mestrado e Doutorado em Administração Universidade Federal de Santa Maria (UFSM), Brasil. 


\section{INTRODUÇÃO}

O modelo de gestão de pessoas vem passando por um contínuo processo de mudanças e modernização. Consequentemente, o mercado de trabalho passou a exigir profissionais altamente qualificados, focados em resultados, resistentes às pressões - internas e externas - e que atendam às suas demandas e necessidades.

Neste sentido, de acordo com Souza et al. (2011), há uma procura crescente por pesquisas na área de Gestão de Pessoas que busquem compreender sua estrutura e o desempenho de acordo com a perspectiva estratégica, partindo do pressuposto de que as pessoas são recursos valiosos e capazes de possibilitar maior vantagem competitiva às organizações.

Knapik (2008) destaca que processos de remuneração, valorização e segurança aos empregados têm um papel importante no gerenciamento de pessoas, proporcionando reconhecimento pelos seus esforços, pela dedicação à empresa. Além disso, a criação ou ampliação de políticas, ações e práticas organizacionais que influenciem positivamente o ambiente de trabalho pode, inclusive, produzir efeitos significativos na prevenção do estresse e Síndrome de Burnout - exaustão por sobrecarga de trabalho, esgotamento emocional - dentre outras iniciativas desta natureza e ainda gerar ou aumentar o bem-estar no ambiente de trabalho (SCHAUFELI et al., 2013).

Dessa forma, emerge nesse contexto o engajamento no trabalho, sendo proposto por Bakker e Leitter (2010), como um fator positivo, relacionado ao bem-estar e/ou à satisfação caracterizada pelo elevado nível de energia e uma forte ligação com o próprio trabalho. Paralelamente, Schaufeli et al. (2002), definem esse mesmo tema como um estado mental positivo relacionado ao trabalho, caracterizado por vigor, dedicação e absorção. Acrescenta-se ainda que organizações que investem em seus profissionais e contam com seu engajamento são mais competitivas, não apenas por serem mais produtivas, mas principalmente pela qualidade diferenciada nos serviços e produtos que oferecem (SCHAUFELI et al., 2013).

Frente a este cenário, como apresentam-se os profissionais pós-graduandos em seu ambiente de trabalho? Energizados, entusiasmados ou imersos no trabalho? Sabe-se, que por meio da realização dos cursos de pós-graduação os indivíduos têm 
a oportunidade de se atualizarem profissionalmente, expandir o rendimento salarial, estender seus contatos e aprimorar os conhecimentos adquiridos na graduação, além de atender às exigências do mercado de trabalho. Logo, a proposta desta pesquisa foi investigar e compreender as percepções de profissionais pós-graduandos sobre engajamento no trabalho, tendo por objetivo específico identificar as variáveis Vigor, Dedicação e Absorção.

De um modo geral, o objetivo desta pesquisa pretende expandir a conceituação do tema e contribuir para a criação de ações e práticas de gestão de pessoas no desenvolvimento humano e organizacional, visto que o engajamento no trabalho produz diversos benefícios, tanto para os profissionais como para as organizações, tornando-se uma das principais ferramentas para ambos atingirem o sucesso.

Sendo assim, a relevância deste estudo pode provocar inúmeras reflexões acerca do engajamento, pois embora possua um papel muito importante para profissionais e organizações, esse tema ainda é pouco explorado por autores brasileiros e pela Administração e Psicologia Organizacional. Portanto, o presente estudo apresenta significância na medida em que contribui na investigação e análise desse fenômeno no contexto acadêmico e gerencial.

\section{FUNDAMENTAÇÃO TEÓRICA}

\subsection{CONCEITO DE ENGAJAMENTO NO TRABALHO}

O conceito de engajamento no trabalho é inicialmente atribuído a Kahn, (1990), ao reconhecer que profissionais engajados, manifestavam-se física, cognitiva, emocionalmente e mentalmente focados no decorrer do desenvolvimento de suas tarefas. Este autor destaca ainda, que a ocorrência desse fenômeno era reconhecida, porque pessoas engajadas apresentavam mais esforços para as atividades e, por isso, notava-se uma identificação do indivíduo com o trabalho. Tal dedicação produzia resultados positivos tanto para a organização quanto para o profissional (SIQUEIRA et al., 2014). 
Nesse mesmo contexto, Bakker et al. (2008) destacam que profissionais com altos níveis de engajamento no trabalho atribuem mais energia e entusiasmo enquanto realizam suas tarefas, além de permanecerem mais focados no seu trabalho. De modo geral, em profissionais com alto nível de engajamento "o cansaço após um dia difícil ou pesado se associa à satisfação em realizar o seu trabalho porque elas percebem que realizam coisas significativas, prazerosas e valiosas" (SCHAUFELI et al., 2013, p. 15).

Em outro momento, Maslach e Leiter, (1997) concluíram que profissionais engajados também eram evidenciados por aspectos positivos, caracterizados por energia, envolvimento e eficácia no desempenho de suas funções. Para os autores, essa concepção relacionada a engajamento no trabalho assumia papel oposto respectivamente às três dimensões do conceito de Burnout - exaustão, cinismo e queda no senso de eficácia profissional, (SIQUEIRA, 2014). Diante disso, outras evidências sobre esse tema foram discordadas e apresentadas por Schaufeli et al. (2002, p. 74), na qual verificava-se que Burnout e engajamento eram estados psicológicos independentes e indicavam características únicas e por isso, não se constituíam como sendo opostos.

Os autores Schaufeli et al. (2013) enfatizam da mesma forma, que engajamento no trabalho é diferente de workabolics, também chamados de viciados no trabalho. Pessoas engajadas no trabalho se dedicam porque sentem prazer no que fazem e não porque sentem compulsão interna em fazê-lo, já os workabolics são pessoas que trabalham muito porque são obcecadas e compulsivas pelo seu trabalho. Assim, segundo Schaufeli, Taris e Van Rheden (2008), a maior diferença entre workabolics e engajamento no trabalho está na motivação para trabalhar e reproduzir esforços em suas atividades.

Dessa maneira, visando identificar o nível de engajamento no trabalho, conforme a concepção citada acima, estudos foram desenvolvidos com a Utrecht Work Engagement Scale (UWES), um instrumento de autorrelato que inclui três dimensões, denominadas Vigor, Dedicação e Absorção, localizadas na tabela a seguir. 
Quadro 1. Variáveis do instrumento de autorrelato

\begin{tabular}{|c|l|}
\hline VARIÁVEIS & \multicolumn{1}{c|}{ CARACTERÍSTICAS } \\
\hline Vigor & $\begin{array}{l}\text { Define-se por altos níveis de energia mental, persistência } \\
\text { para vencer as dificuldades e desejo de investir esforços } \\
\text { durante a realização das atividades no trabalho. }\end{array}$ \\
\hline Dedicação & $\begin{array}{l}\text { Elevado grau de comprometimento e entusiasmo } \\
\text { com uma atividade, o qual proporciona ao indivíduo } \\
\text { vivenciar a sensação de prazer, inspiração, desafio e } \\
\text { reconhecimento. }\end{array}$ \\
\hline Absorção & $\begin{array}{l}\text { Nível intenso de concentração e atenção, o qual o } \\
\text { trabalhador perde a noção do tempo e apresenta } \\
\text { dificuldade em desvincular-se do trabalho. }\end{array}$ \\
\hline
\end{tabular}

Fonte: Schaufeli e Bakker (2003).

Esse instrumento (UWES) também é apresentado na versão, português brasileiro, e foi traduzida pelos autores Angst, Benevides-Pereira, Porto-Martins (2009). A versão é composta por 17 itens, com escala tipo Likert de sete categorias, (de " $0=$ nunca" até "6 = sempre"), composto por seis itens de Vigor, cinco itens de Dedicação e seis itens de Absorção.

A avaliação do engajamento no trabalho prevê verificar o quanto o profissional encontra-se empenhado na realização das suas atividades. O instrumento (UWES) é validado em diversos países e em todos os estudos foi utilizada Análise Fatorial Confirmatória, que produziu índices de ajustes para o modelo de três fatores, além de terem sido observados índices satisfatórios de precisão para as três escalas apresentadas (SIQUEIRA et al., 2014).

Na tabela a seguir serão apresentadas algumas contribuições de autores sobre a importância do engajamento no trabalho. 
Quadro 2. Contribuições de autores

\begin{tabular}{|l|l|}
\hline \multicolumn{2}{|c|}{ ENGAJAMENTO NO TRABALHO } \\
\hline BAKKER; LEITER (2010) & $\begin{array}{l}\text { Indivíduos engajados demonstram desempenho maior no trabalho e } \\
\text { exibem melhores resultados nos setores em que atuam; }\end{array}$ \\
\hline SCHAUFELI (2013) & $\begin{array}{l}\text { Pessoas engajadas no trabalho são leais às suas organizações e a taxa } \\
\text { de rotatividade de funcionários é menor entre elas. }\end{array}$ \\
\hline $\begin{array}{l}\text { BAKKER; DEMEROUTI; } \\
\text { SANZ-VERGEL (2014) }\end{array}$ & $\begin{array}{l}\text { Indivíduos engajados apresentam níveis superiores de } \\
\text { comportamento extra função, realizando ações que vão além de suas } \\
\text { responsabilidades básicas. }\end{array}$ \\
\hline $\begin{array}{l}\text { TRACY; MATTA; VICTORIA } \\
\text { (2016) }\end{array}$ & $\begin{array}{l}\text { Engajar-se com a profissão compreende o engajamento com a } \\
\text { organização, a liderança, o trabalho e as tarefas, o time e os colegas. }\end{array}$ \\
\hline
\end{tabular}

Fonte: Dados da pesquisa

Diante do exposto, observa-se que engajamento no trabalho traz muitos benefícios para a organização e para o profissional, visto que, funcionários que se sentem mais engajados com seu trabalho apresentam níveis mais elevados de comprometimento afetivo e normativo. Além disso, as emoções positivas vivenciadas pelas pessoas no trabalho funcionam como uma espiral positiva, que se mantém de forma contínua e crescente através do aumento de recursos (do trabalho e individuais), que em geral, conduz para a elevação do nível de engajamento, produzindo resultados efetivos e positivos, e consequentemente a satisfação, motivação e clima positivo na organização, (TRACY; MATTA; VICTORIA, 2016; SCHAUFELI et al., 2013).

\section{METODOLOGIA}

A proposta desta pesquisa é investigar e compreender as percepções de profissionais pós-graduandos sobre engajamento no trabalho, tendo por objetivo identificar as variáveis Vigor, Dedicação e Absorção. Assim sendo, a metodologia utilizada neste estudo foi de cunho quantitativo de natureza descritiva, ou seja, quando almeja-se a descrição das características de determinada população ou fenômeno, ou então, o estabelecimento de relações entre variáveis, (GIL, 2011) e a técnica utilizada para essa abordagem de pesquisa foi o método Survey. 
O estudo foi realizado em uma Instituição de Ensino Superior Privada e contou com a participação de 147 profissionais pós-graduandos em diferentes cursos de uma Instituição de Ensino Superior Privada: Ciências da Saúde com 37, Ciências Humanas com 24, Ciências Sociais com 51 e Ciências Tecnológicas com 35 pós-graduandos.

Na coleta de dados, foi aplicado o questionário de autorrelato sobre engajamento no trabalho, Utrecht Work Engagement Scale (UWES) de Schaufeli e Bakker (2003), sendo estruturadas 17 questões com escala Likert, de sete categorias, (de "0 $=$ nunca" até " $6=$ sempre"). Junto ao questionário foi entregue o Termo de Consentimento Livre e Esclarecido, explicando ao pós-graduando o objetivo do trabalho e das questões, como também a solicitação do retorno do mesmo assinado pelo participante.

Para o preenchimento do instrumento não foi necessária a identificação dos participantes, uma vez que a pesquisa é de caráter sigiloso. Sendo que, para a coleta, foram percorridas as salas de aula das turmas de pós-graduação da IES, onde foram explicados os objetivos para os participantes do estudo para posterior preenchimento do questionário da pesquisa.

Para a pesquisa quantitativa, foi utilizado a técnica de análise de frequência, média, desvio padrão e análise fatorial, sendo que, os dados obtidos foram analisados através do software SPSS (Statistical Package for the Social Sciences). Primeiramente foram observados os dados do perfil da amostra e em seguidas as variáveis referentes a engajamento no trabalho - Vigor, Dedicação, Absorção.

\section{ANÁLISE DOS RESULTADOS}

Nesta etapa do trabalho apresenta-se a análise dos dados retirados dos questionários aplicados aos pós-graduandos da Instituição de Ensino Superior Privada. Nesse ponto, os resultados serão divididos para melhor identificação, análise e interpretação dos dados. Primeiramente, será levantado o perfil predominante da amostra (variáveis, frequência e porcentagem) e em seguida apresentados os resultados da análise do engajamento no trabalho (itens, médias e desvio padrão). 


\subsection{PERFIL DOS ENTREVISTADOS}

Através das análises dos questionários, identificou-se o perfil predominante da amostra composta por 147 profissionais pós-graduandos, como mostra a tabela a seguir.

Tabela 1. Perfil dos entrevistados

\begin{tabular}{cccc}
\hline VARIÁVISIS & DESCRIÇÃo & FREQUÊNCIA & $\%$ \\
\hline \multirow{2}{*}{ Faixa etária } & 20 a 29 anos & 99 & 67,34 \\
& 30 a 39 anos & 34 & 23,13 \\
& 40 ou acima & 14 & 9,53 \\
\hline \multirow{2}{*}{ Gênero } & Feminino & 104 & 70,75 \\
& Masculino & 43 & 2 \\
\hline \multirow{2}{*}{ Estado civil } & Casado(a)/União Estável & 44 & 29,9 \\
& Solteiro(a) & 101 & 68,7 \\
& Outros (Separado ou Viúvo) & 2 & 1,4 \\
\hline \multirow{2}{*}{ Tempo de profissão e/ou empresa } & Até 1 ano & 86 & 58,5 \\
& Entre 2 e 10 anos & 40 & 27,21 \\
& Acima de 10 anos & 12 & 8,16 \\
& Não responderam & 9 & 6,13 \\
\hline \multirow{2}{*}{ Carga horária semanal } & Até 20 horas & 35 & 23,80 \\
& 21 a 30 horas & 11 & 7,48 \\
& 31 a 40 horas & 57 & 38,78 \\
& 41 a 60 horas & 33 & 22,45 \\
& Não responderam & 11 & 7,49 \\
\hline
\end{tabular}

Fonte: Dados da pesquisa

Conforme resultados apresentados na tabela, observa-se que a média da faixa etária ficou entre 20 a 29 anos, representando 67,34\% dos respondentes, seguido da faixa entre 30 a 39 anos (23,13\%). Em relação ao gênero, verifica-se que a maioria da amostra é composta pelo gênero feminino (70,75\%) em comparação ao gênero masculino (29,25\%). 
No que diz respeito ao estado civil, percebe-se que $68,7 \%$ dos participantes são solteiros(as), seguido dos casados(a)/união estável (29,9\%). Logo após verificase que o tempo de profissão e/ou empresa corresponde até 1 ano (58,50\%). Já no que se refere à carga horária evidencia-se de 31 a 40 horas trabalhadas (38,78\%).

Assim sendo, pode-se observar que os dados contidos na tabela revelam que a maioria dos participantes eram do gênero feminino (70,75\%), com idade média de 20 a 29 anos (67,34\%), sendo a maior parte solteiros(as) 68,7 \%, com o tempo de profissão e/ ou empresa de até 1 ano (58,20 \%) e carga horária de 31 a 40 horas $(38,78 \%)$.

\subsection{ANÁLISE DO ENGAJAMENTO NO TRABALHO}

Para melhor entendimento da análise realizada, três tabelas serão apresentadas a seguir com as respectivas variáveis, Vigor, Dedicação e Absorção. O primeiro quadro detalhado foi a variável Vigor (V), composta por 6 itens, o segundo foi Dedicação (D) composta por 5 itens e por fim, a variável Absorção (A), composta por 6 itens, assim como, a média e o desvio padrão correspondente a cada um dos itens.

Tabela 2. Variável Vigor, composto por seis itens

\begin{tabular}{rlrc}
\hline ITEM & \multicolumn{1}{c}{ VIGOR } & MÉDIA & D. P. \\
\hline V1 & $\begin{array}{l}\text { Em meu trabalho, sinto-me repleto (cheio) de } \\
\text { energia }\end{array}$ & 4,63 & 1,05 \\
\hline V2 & $\begin{array}{l}\text { No trabalho, sinto-me com força e vigor } \\
\text { (vitalidade). }\end{array}$ & 4,58 & 1,14 \\
\hline V3 & $\begin{array}{l}\text { Quando me levanto pela manhã, tenho vontade } \\
\text { de ir trabalhar. }\end{array}$ & 4,65 & 1,07 \\
\hline V4 & $\begin{array}{l}\text { Posso continuar trabalhando por longos } \\
\text { períodos de tempo. }\end{array}$ & 4,68 & 1,14 \\
\hline V5 & $\begin{array}{l}\text { Em meu trabalho, sou uma pessoa mentalmente } \\
\text { resiliente (versátil). }\end{array}$ & 5,03 & 1,08 \\
\hline V6 & $\begin{array}{l}\text { No trabalho, sou persistente mesmo quando as } \\
\text { coisas não vão bem. }\end{array}$ & 5,01 & 1,06 \\
\hline
\end{tabular}

Fonte: Schaufeli e Bakker (2003) 
Observa-se de acordo com o quadro 5, que a maior média está localizada no item V5 (5,03), referindo-se à "resiliência mental", "no qual diz respeito à habilidade que um indivíduo possui de adaptar-se positivamente perante situações estressantes e adversas, emergindo das dificuldades como uma pessoa mais forte e competente", (TRACY; MATTA; VICTORIA, 2016, p. 42). Nesse contexto, Schaufeli et al. (2013), descrevem pessoas que empregam a resiliência como estratégia de adaptação positiva e sucessiva, geralmente são engajadas, otimista e autoconfiantes.

O segundo item a apresentar a maior média foi V6 $(5,01)$, na qual evidenciase a persistência do indivíduo no trabalho, ou seja, aquele que insiste em algo, mesmo quando as coisas não vão bem. Os resultados apontam também para um desvio padrão baixo dessas questões V5 $(1,08)$ e V6 $(1,06)$, onde revela-se menor dispersão das respostas, isto é, número elevado de pessoas sentem-se do mesmo modo.

Em seguida, aparecem a terceira e a quarta maiores médias, na qual localizam-se no item V3 $(4,65)$, quando o indivíduo ao acordar pela manhã sente vontade de ir trabalhar e $\mathrm{V} 4(4,68)$ quando a pessoa pode continuar trabalhando por longos períodos de tempo. Os resultados também apontam para as duas menores médias nos itens V1 $(4,63)$ e V2 $(4,58)$, na qual referem-se à "energia" e "vitalidade", isto é, os indivíduos apresentam elevados níveis de energia e vitalidade enquanto trabalham. Também é importante salientar que desvio padrão dos itens V2 $(1,14)$ e V4 $(1,14)$, são iguais e os maiores apresentados no quadro, portanto pode ter ocorrido oscilações em relação as outras respostas.

Pode-se concluir por meio desta análise detalhada que os profissionais pós-graduandos que apresentaram médias altas do constructo em relação a variável Vigor, geralmente são pessoas identificadas com elevados níveis de energia e resiliência mental, assim como, persistência para vencer as dificuldades e desejo para investir esforços enquanto trabalham.

Partindo do pressuposto, interessante observar que são características de jovens que aspiram crescimento no mercado de trabalho, visto que, querem aprofundar seus conhecimentos, aumentar a capacidade profissional, diferenciar-se dos concorrentes e proporcionar a chance de ganhos mais expressivos através de uma pós-graduação. Considerando o trabalho, o vigor relaciona-se à energia fornecida nas atividades executadas. Para além disso, estão presentes a persistência, os esforços e a vontade ao dedicar-se em cada projeto (BAKKER; LEITER, 2010). 
Tabela 3. Variável Dedicação, composto por cinco itens

\begin{tabular}{clcc}
\hline ITEM & \multicolumn{1}{c}{ DEDICAÇÃo } & MÉDIA & D. P. \\
\hline D1 & $\begin{array}{l}\text { Eu acho que o trabalho que realizo é cheio } \\
\text { de significado e propósito. }\end{array}$ & 5,12 & 1,20 \\
D2 & Estou entusiasmado com meu trabalho. & 4,73 & 1,36 \\
\hline D3 & Meu trabalho me inspira. & 4,81 & 1,17 \\
\hline D4 & $\begin{array}{l}\text { Estou orgulhoso com o trabalho que } \\
\text { realizo. }\end{array}$ & 5,09 & 0,92 \\
\hline D5 & Para mim, meu trabalho é desafiador. & 4,97 & 1,3 \\
\hline
\end{tabular}

Fonte: Schaufeli e Bakker (2003)

A segunda variável detalhada foi a Dedicação (D), no qual observa-se de acordo com o quadro 6, que o tópico com a maior média está localizada no item D1 $(5,12)$, onde demonstra que o profissional é realizado, uma vez que o trabalho que ele faz tem significado e propósito. Em seguida, com a segunda maior média está o item D4 $(5,09)$, que comprova que o indivíduo tem orgulho do trabalho que realiza. Observa-se também que este item apresenta o menor desvio padrão $(0,92)$, dentre todas as respostas.

Em terceiro e quarto lugares em que as médias são mais elevadas, aparecem os itens D5 $(4,97)$ "trabalho desafiador" e D3 $(4,81)$ "trabalho me inspira". Já a última média analisada, por conseguinte a menor, está no item D2 (4,73), referindo-se a "entusiasmo no trabalho", ou seja, supõem-se que os estudantes apresentam uma motivação reduzida ou falta de estímulo com o trabalho, no entanto, este item obteve o maior desvio padrão $(1,36)$ em relação aos demais, demonstrando assim, uma maior dispersão nas respostas.

Portanto, os profissionais pós-graduandos que apresentam elevadas médias na variável Dedicação, normalmente, identificam-se fortemente com seu trabalho e se orgulham, porque a experiência é significativa, inspiradora e desafiadora. 
Tabela 7. Variável Absorção, composto por cinco itens

\begin{tabular}{|c|l|c|c|}
\hline ITEM & \multicolumn{1}{|c|}{ ABSORÇÃO } & MÉDIA & D. P. \\
\hline A1 & $\begin{array}{l}\text { 1. O “tempo voa” quando estou } \\
\text { trabalhando. }\end{array}$ & 4,72 & 1,21 \\
\hline A2 & $\begin{array}{l}\text { 2. Quando estou trabalhando, esqueço tudo } \\
\text { o que se passa ao meu redor. }\end{array}$ & 4,06 & 1,35 \\
\hline A3 & $\begin{array}{l}\text { 3. Sinto-me feliz quando trabalho } \\
\text { intensamente. }\end{array}$ & 4,61 & 1,31 \\
\hline A4 & $\begin{array}{l}\text { 4. Sinto-me envolvido com o trabalho que } \\
\text { faço. }\end{array}$ & 5,11 & 1,10 \\
\hline A5 & 5. "Deixo-me" levar pelo meu trabalho. & 4,43 & 1,21 \\
\hline A6 & 6. É difícil desligar-me do meu trabalho. & 3,94 & 1,5 \\
\hline
\end{tabular}

Fonte: Schaufeli e Bakker (2003)

A terceira e última variável detalhada foi Absorção, onde percebe-se que o indivíduo está envolvido com o trabalho que faz, pois o item A4 $(5,11)$ apresentou a maior média. Em seguida, aparece o item A1 $(4,72)$, no qual aponta que o "tempo voa", ou seja, quando o profissional está no ambiente de trabalho ele perde a noção do tempo.

A próxima média mais elevada aparece no item A3 $(4,61)$, na qual o indivíduo sente-se feliz quando trabalha intensamente. Em quarto e quinto lugares em que as médias são maiores aparecem os itens A5 (4,43) "deixo-me" levar pelo meu trabalho e A2 (4,06), "quando estou trabalhando, esqueço tudo o que se passa ao meu redor". Isso demonstra que o profissional está em um nível intenso de concentração e atenção e por isso, nada importa ao seu redor.

Já o último item analisado, consequentemente, aponta para a menor média A6 (3,94), "é difícil desligar-me do meu trabalho", ou seja, o profissional apresenta dificuldade em desvincular-se do trabalho. Vale ressaltar que este item também apresentou maior desvio padrão $(1,59)$ demonstrando assim, uma maior dispersão nas respostas.

Por fim, indo ao encontro das análises pode-se constatar que os profissionais pós-graduandos que apresentam médias altas na variável Absorção, sentem que estão envolvidos com o trabalho que realizam, acabam por perderem a noção do 
tempo, assim como evidencia o autor Chér (2014, p. 21), "ficamos absorvidos de modo profundo, com foco e entrega. As horas passam e você não percebe, ficando a sensação de que se passaram apenas alguns minutos", assim como, sentem-se felizes ao trabalharem intensamente.

De uma maneira geral, observa-se que a maior média entre todos os itens das três variáveis apresenta-se em Dedicação, no item D1 $(5,12)$, "eu acho que o trabalho que realizo é cheio de significado e propósito", e que a menor média entre todos os itens das três variáveis apresenta-se em Absorção, no item A6 $(3,94)$, "é difícil desligar-me do meu trabalho", ou seja, demonstra que dos 147 profissionais que participaram da pesquisa, a maioria apresenta pouca dificuldade em desvincular-se do trabalho. Vale destacar que este item também apresentou o maior desvio padrão $(1,59)$ entre todos os itens, demonstrando assim, uma maior dispersão nas respostas.

A tabela a seguir representa as médias gerais e os desvios padrões de cada variável. Observa-se que as médias ficaram próximas e acima de 4.

Tabela 8. Média geral e Desvio Padrão das variáveis

\begin{tabular}{|c|c|c|}
\hline VARIÁVEL & MÉDIA & D. P. \\
\hline VIGOR & 4,76 & 1,09 \\
\hline DEDICAÇÃO & 4,94 & 1,19 \\
\hline ABSORÇÃO & 4,47 & 1,29 \\
\hline
\end{tabular}

Fonte: Elaborada pela autora

De todo o contexto apresentado conclui-se, portanto, que os profissionais pós-graduandos em seu ambiente de trabalho referindo-se às percepções sobre engajamento, apresentaram a maior média na variável Dedicação $(4,94)$, como mostra o quadro 8. Em seguida aparece Vigor $(4,76)$ em último lugar aparece Absorção $(4,47)$, que apresentou a menor média no geral.

Nota-se por meio da análise dos resultados que a maioria dos profissionais pós-graduandos pesquisados tem idade entre 20 a 29 anos, ou seja, são jovens da geração Y. De acordo com Lancaster e Stillman (2011, p. 18) "a geração Y é formada por jovens nascidos aproximadamente entre os anos de 1982 a 2000". Os autores 
acreditam que esta nova geração está dominando o mercado de trabalho e continua adquirindo novas experiências com sua disposição em aprender e inovar para promover melhorias aos processos, buscam sempre significados em suas tarefas para saber a importância de seu trabalho na organização.

Portanto, partindo do pressuposto que a dedicação que estes profissionais apresentam, possibilita uma forte identificação com seu trabalho, envolvendo-se completamente com o que fazem, experimentando um senso de significado, entusiasmo e desafio, a fim de atingirem os seus propósitos.

Para os autores, Salanova et al. (2000); Schaufeli et al.(2002); Bakker e Leiter (2010), a dedicação está na afeição e consideração em alto grau na realização das tarefas; tem-se ainda, o gosto prazeroso pelo trabalho à medida que o vê como desafiador e carregado de significados.

Por fim, Absorção apresentou a menor média, ou seja, isso possibilita identificar que os estudantes pesquisados apresentam pouca dificuldade em desligar-se do trabalho, como mostra a análise do perfil dos entrevistados, o tempo de profissão e/ou empresa de até 1 ano, partindo do pressuposto, que também pode ser considerado uma característica da geração Y, que como destaca o autor Oliveira (2010), é um indivíduo inquieto, impaciente, que deseja soluções imediatas. Está sempre em busca de novos desafios e deseja subir na carreira constante e rapidamente, isto é, do mesmo modo que possuem facilidades de se ajustarem às mudanças também não conseguem ficar muito tempo realizando a mesma atividade, buscam sempre novos aprendizados e desafios, em troca aspiram reconhecimento e plano de carreira. Assim, "a simples troca de emprego já não está associada apenas a benefícios financeiros e sim à falta de desafios coerentes para as expectativas dos jovens" (OLIVEIRA, 2010, p. 131).

Assim sendo, os resultados evidenciaram que a maioria dos profissionais pós-graduandos identificam-se com seu trabalho, uma vez que as atividades que desempenham possuem significado e propósito, porém, esses profissionais também apresentam pouca dificuldade em desligar-se do trabalho, características presentes na geração Y. 


\section{CONSIDERAÇÕES FINAIS}

No decorrer do estudo notou-se que profissionais engajados apresentam melhores resultados e desempenho, atuam com comprometimento e estão conectados com os objetivos da empresa.

Portanto, tendo em vista que o objetivo geral desta pesquisa foi analisar e compreender a percepção dos profissionais pós-graduandos, pode-se interpretar que o estudo atingiu os objetivos propostos inicialmente. Verificou-se que, de um modo geral, o perfil dos entrevistados constitui-se em sua maioria por participantes do gênero feminino, idade média de 20 a 29 anos, sendo a maior parte solteiros(as), com o tempo de profissão e/ou empresa de até 1 ano, e carga horária de 31 a 40 horas.

No que condiz a média geral das três variáveis, Dedicação foi a que alcançou a maior média $(4,94)$ em relação a Vigor $(4,76)$ que aparece em segundo lugar e Absorção $(4,47)$ apresentando a menor média no geral. Nota-se, por meio da análise dos resultados que a maioria dos profissionais pós-graduandos pesquisados tem idade entre 20 a 29 anos, ou seja, idade dos jovens da geração Y.

Partindo do pressuposto que a dedicação que estes profissionais apresentam, possibilita uma forte identificação com seu trabalho, envolvendo-se completamente com o que fazem e experimentando um senso de significado, entusiasmo e desafio, a fim de atingirem os seus propósitos.

Assim como os estudantes que apresentaram a menor média em Absorção, isto quer dizer que a maioria não apresenta dificuldades em desligar-se do trabalho e/ou não estão em um nível intenso de concentração e atenção. Podendo ser considerado também uma característica da geração Y, por ser uma geração de pessoas ansiosas e impacientes, quer dizer, do mesmo modo que possuem facilidades de se ajustarem às mudanças, também não conseguem ficar muito tempo realizando a mesma atividade, buscam sempre novos aprendizados e desafios, em troca aspiram reconhecimento e plano de carreira.

Por fim, o estudo apresenta relevância pelo fato de que o engajamento no trabalho, embora possua um papel muito importante para o profissional e para a organização, ainda é pouco explorado pelas empresas e gestores, assim como, por autores brasileiros e pela Administração e Psicologia Organizacional. 
Portanto, esta pesquisa apresenta significância na medida em que contribui para investigação e análise desse fenômeno no contexto acadêmico e para futuras práticas da gestão de pessoas nas empresas, levando em consideração todo o benefício que o engajamento no trabalho pode proporcionar. Desse modo, em futuras investigações sugere-se ampliar pesquisas sobre o tema, uma vez que, "pessoas engajadas geram benefícios e consequências positivas para si, para seus colegas e para a organização" (SCHAUFELI et al., 2013, p. 46).

\section{REFERÊNCIAS}

AGNST; R.; BENEVIDES-PEREIRA; A. M. T.; PORTO-MARTINS, P. C. Utrecht Work Engagement Scale. Tradução de W. B. Schaufeli e A. B. Bakker. Curitiba: GEPEB, 2009.

BAKKER, A. B. et.al. Work Engagement: an emerging concept in ocupational health psychology. Work \& Stress, v.22, p. 187-200, 2008.

BAKKER, A. B.; DEMEROUTI, E. Towards a model of Work Engagement. Career Development International, v. 13 n.3, p.209-223, 2008.

BAKKER, A. B.; DEMEROUTI, E; SANZ-VERGEL, A. I. Burnout and Work Engagament: The JD: R Approach. Annual Review of Organization Psychology and Organization Behavior, v.1, 2014. p.389-411.

BAKKER, A. B.; LEITER, M. P. Where to go from here: integration and future research on work engagement. In: BAKKER, A. B.; LEITER, M. P. (Org.). Work Engagement: a handbook of essential theory and research. New York: Psychology Press, 2010. P.181-196.

CARVALHO, S. R. A Influência da Compatibilidade pessoa-trabalho sobre o engajamento no trabalho. 2015. Dissertação (Mestrado em Administração) - Universidade Metodista de São Paulo, São Bernardo do Campo, 2015. 
CHÉR, R. Engajamento: melhores práticas de liderança, cultura organizacional e felicidade no trabalho. Rio de Janeiro, RJ: Alta Books, 2014.

FREITAS, L. A. V.; CHARÃO-BRITO, L. Engajamento no trabalho: um estudo em profissionais multidisciplinares de saúde em um município da região sul. Revista Cesumar Ciências Humanas e Sociais Aplicadas, v. 21, n.2, p. 407-419, jul./dez. 2016.

GIL, A. C. Métodos e técnicas de Pesquisa social. 6. ed. São Paulo: Atlas, 2011.

KNAPIK, J. Gestão de Pessoas e Talento. 2. ed. Curitiba: IBPEX, 2008.

LANCASTER, L. C.; STILLMAN, D. O Y da questão: Como a geração Y está transformando o mercado de trabalho. Tradução de Leandro Woyakoski. São Paulo: Saraiva, 2011.

MASLACH, C.; LEITER, M. P. The Truth about Burnout: how organizations cause personal stress and what to do about it. San Francisco: Jossey-Bass, 1997.

OLIVEIRA, S. Geração Y: o nascimento de uma nova versão de líderes. São Paulo: Integrare, 2010.

SALANOVA, M.; SCHAUFELI, W. B.; LLORENS, S.; PEIRÓ, J. M.; GRAU, R. Desde el "Burnout" al "Engagement": ¿una Nueva perspectiva? Revista de Psicología del trabajo y de las organizaciones, v. 16, n. 2, p. 117-134, 2000.

SCHAUFELI, W. B.; BAKKER, A. B. UWES- Utrecht Work Engagement Scale: Preliminary Manual. Occupational Health Psychology Unit Utrecht University, 2003.

SCHAUFELI, W. B. et.al. The Measurement of Engagement and Burnout: a two sample confirmatory factor analytic approach. Journal of Happiness Studies, v. 3, p. 71-92, 2002.

SCHAUFELI, W.; DIJKSTRA, P.; VAZQUEZ, A. C. O Engajamento no Trabalho. São 